\title{
La digitalización de las masas y los riesgos del dataísmo.
}

\section{The digitization of the masses and the risks of dataism.}

\author{
David Álvarez Antelo ${ }^{1}$ \\ J osé María Enríquez Sánchez ${ }^{2}$ \\ Fecha de recepción: 8/06/2020 - Fecha de aceptación: 23/07/2020
}

DOI : https://doi.org/10.22490/26655489.3913

\section{Resumen}

La obsesión por la acumulación de datos está detrás de los propósitos entusiasmantes puestos en las posibilidades de las tecnologías para la información y la comunicación. Desde esta sola perspectiva suele ser bastante corriente hablar de oportunidades y, asociadas a ello, de retos. Pero estos desafíos se enfocan en favorecer la expansión de estas tecnologías a cualquier ámbito que se antoje. En medio de esta exaltación resultan menores las atenciones puestas en los riesgos a la exclusión, pero también al control y la dominación que este pueda implicar. Precisamente contrarrestar estos peligros es uno de los grandes retos del derecho para salvaguardar las garantías civiles y políticas de los miembros de la sociedad democrática o, de lo contrario, coadyuvar en el establecimiento de regímenes totalitarios, igualmente sujetos a la legalidad, pero no a la idea de justicia. Esta preocupación es la que trataremos de explicitar volviendo para ello sobre la falsa dicotomía que se establece entre libertad y seguridad sobre la que abunda el llamado derecho penal del enemigo y cuanto ello comporta de quiebra de sistema de garantías en un Estado democrático y de derecho.

1 Ingeniero industrial superior e investigador del Grupo de investigación reconocido en energía, economía y dinámica de sistemas (GEEDS) de la Universidad de Valladolid (UVa). ORCID: 0000-0001-9738-3981. david.alvarez.antelo@gmail.com

2 Investigador posdoctoral en la Universidad de Valladolid y miembro del Grupo de investigación reconocido en ciencias sociales aplicadas. ORCID: 0000-0003-1597-9250. josemaria.enriquez@uva.es 
Palabras clave: Tecnologías de la información y comunicación, big data, inteligencia artificial, dataísmo, discriminación predictiva, derecho penal del enemigo, oclocracia, perfilación discriminatoria.

\section{Abstract}

The obsession with data accumulation is behind the exciting purposes put into the possibilities of information and communication technologies. From this single perspective it is usually quite common to talk about opportunities and, associated with it, challenges. But these challenges are focused on favoring the expansion of these technologies to any area that suits them. In the midst of this exaltation, less attention is paid to the risks of exclusion, but also to the control and domination that this may imply. Precisely counteracting these dangers is one of the great challenges of the Law to safeguard the civil and political guarantees of the members of the democratic society or, otherwise, to contribute to the establishment of totalitarian regimes, equally subject to legality, but not to the idea of justice. This concern is what we will try to make explicit by returning to it about the false dichotomy that is established between freedom and security, on which the so-called criminal law of the enemy abounds and how much this involves the failure of the system of guarantees in a democratic and legal State.

Key Words: Information and communication technologies, big data, artificial intelligence, dataism, predictive discrimination, criminal law of the enemy, ochlocracy, discriminatory profiling.

\section{I ntroducción}

A pesar de los llamamientos de la comunidad internacional para reducir las emisiones de $\mathrm{CO}_{2}$ a la atmósfera, cada vez es mayor la concentración de estos gases de efecto invernadero; con lo que, ante la imposibilidad de mitigación de los efectos previstos por el cambio climático, en la actualidad se habla cada vez con más insistencia de esfuerzos de adaptación, previsiblemente mayores cuanto más grande sea esa el nivel de emisiones. 
Posiblemente el lector se halle sorprendido de este comienzo en la presunción de que no sea este el tema de estudio o reflexión a los que este número de revista concita. Sin embargo, veremos que esta entradilla tiene su motivo: por ejemplo, si quisiéramos señalar las ventajas de la inteligencia artificial y el big data precisamente para llevar a cabo cuantos análisis y proyecciones de las cuales se aprovecha el IPCC y, por ende, la comunidad internacional, para la toma de decisiones este respecto.

He aquí, pues, una de las grandes ventajas. Lo que ya no parece tan claro es la alusión primera a la huella de carbono. Si bien la explicación es bastante sencilla: gracias a las posibilidades de las tecnologías de la información y la comunicación, cada vez generamos más datos.

Cada año crece el número de usuarios de internet: en enero del año 2019 había unos 4390 millones, cifra que supone un incremento del $9 \%$ respecto del año anterior, y aumenta tanto el número de aplicaciones como la velocidad a la que se pueden enviar los datos (de hecho, se estima que la adopción de la tecnología $5 \mathrm{G}$ permitirá aumentar hasta 20 veces la velocidad de envío y descarga de información).

Cada minuto se generaron y enviaron más de 55000 posts en Instagram y más de 500000 en Twitter en el año 2019, lo que supone 5 veces más tweets y 15 veces más post en Instagram que en el año 2013 (Ilustración 1).

Ilustración 1. Generación de datos cada minuto.

Posts o tweets/min

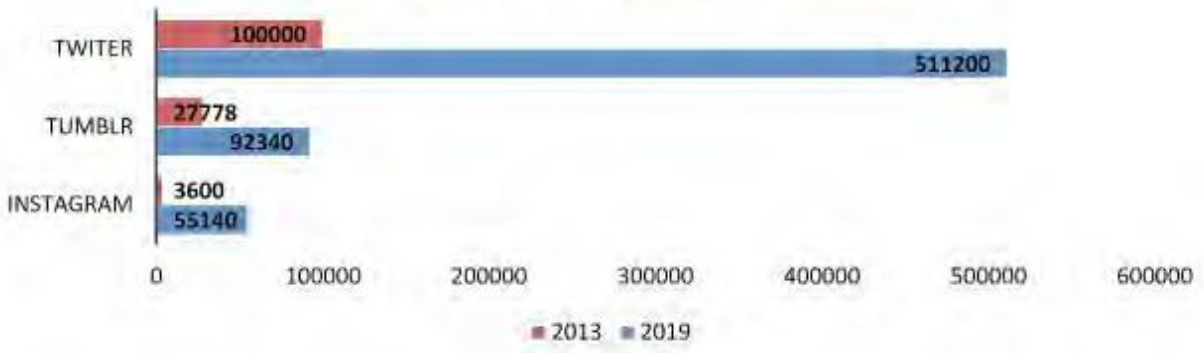

Fuente: Elaboración propia a partir de la empresa de datos e inteligencia de negocio Domo $^{3}$

3 https://www.domo.com/learn\#/ 
Cada día se generan 4 petabytes de datos en Facebook y 4 terabytes de datos son enviados por cada coche conectado; se envían 294000 millones de emails, 65000 millones de mensajes en WhatsApp, 500 millones de tweets y se realizan 5 000 millones de búsquedas en la red.

Según el Foro Económico Mundial (o Foro de Davos), entre el año 2013 y el 2020 se ha multiplicado por diez el total de datos acumulados digitales, y se estima que en el año 2025 se crearán más de 460 exabytes de datos diariamente (el equivalente a casi 213 millones de DVD cada día) ${ }^{4}$.

Si expandimos la visión al total de lo que sucedió cada minuto durante el año 2019 en la red de redes, los datos son abrumadores: 4,5 millones de videos transmitidos mediante YouTube, casi 700000 horas visualizadas en Netflix, 390000 Apps descargadas, 18 millones de mensajes de texto enviados, 2,1 millones de Snaps creados, 4,8 millones de Gifs enviados, o cerca de 200 millones de emails enviados.

\section{I lustración 2: What happens in an internet minute, 2019.}

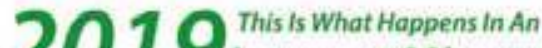 \\ 2019 Internet Minute}

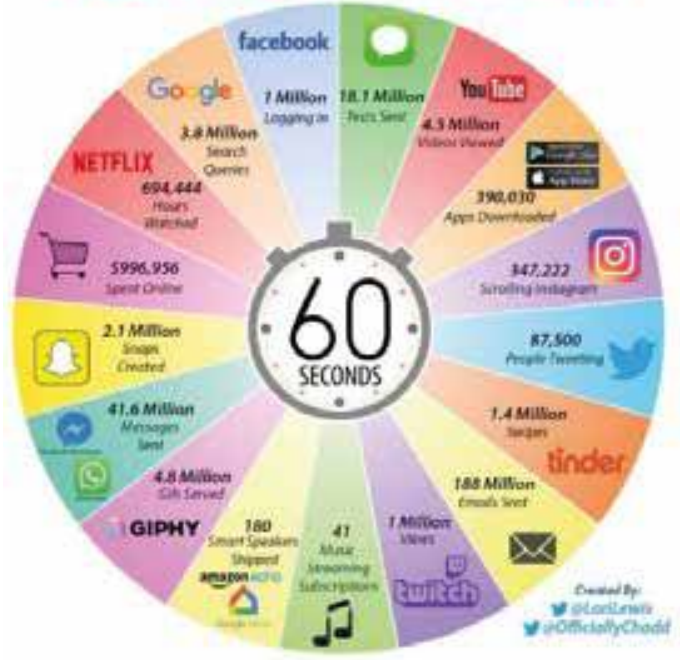

Fuente: Infografía creada por Lori Lewis ${ }^{5}$ y Chadd Callahan

\footnotetext{
4 https://www.weforum.org/agenda/2019/04/how-much-data-is-generated-eachday-cf4bddf29f/

5 https://www.allaccess.com/merge/archive/29580/2019-this-is- what-happens-inan-internet-minutea
} 
Y en lo que llevamos del año 2020 los datos observados indican que la tendencia en la creación y distribución de datos en la red no hace sino aumentar de forma desproporcionada, como podemos apreciar en la imagen actualizada al 2020.

Ilustración 3. What happens in an internet minute,
2020.

\section{Internet Minute}

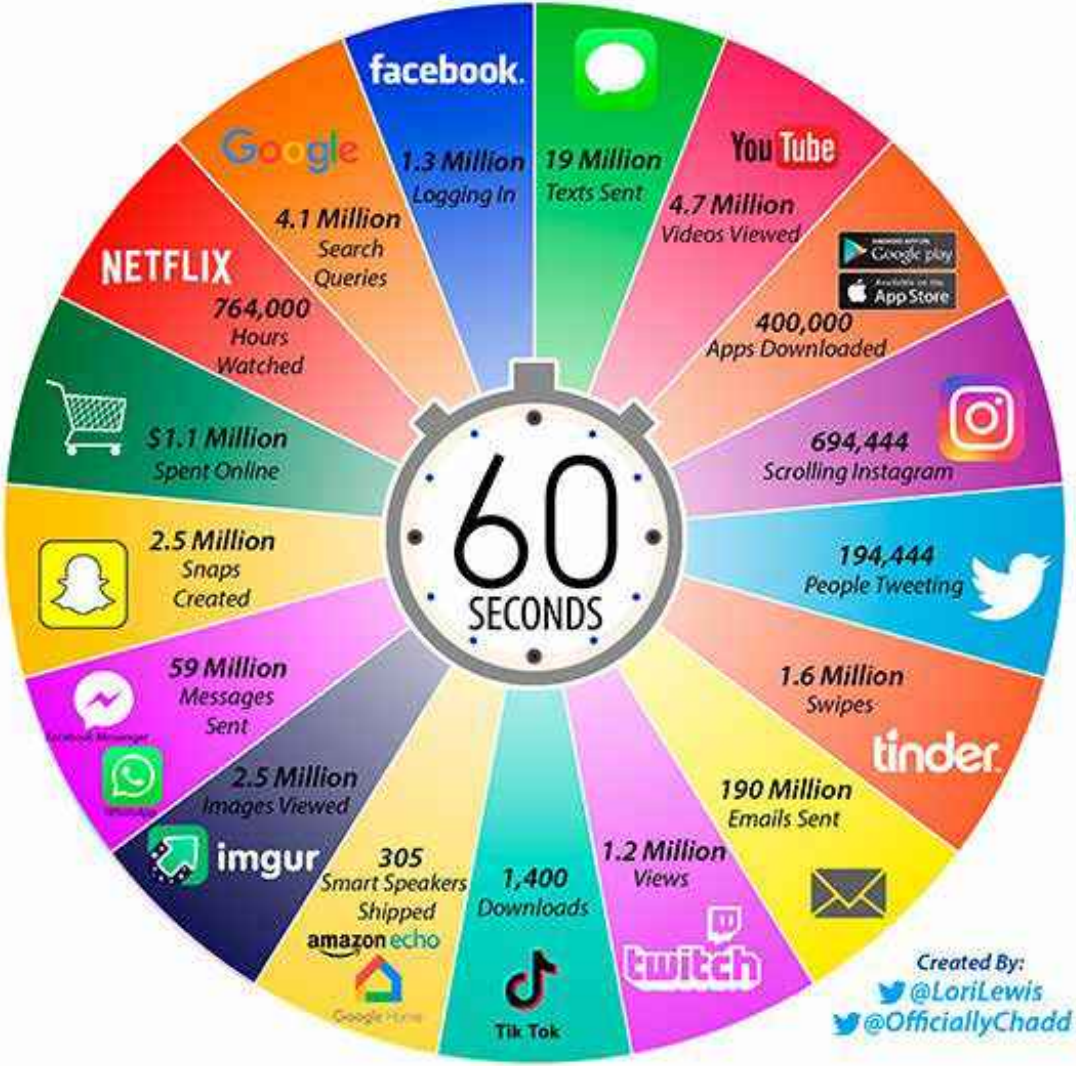

Fuente: Infografía creada por Lori Lewis ${ }^{6}$ y Chadd Callahan

Sin embargo, estas muestras no son más que un inicio del problema: el aumento del número de usuarios conectados mediante dispositivos móviles, la llegada del 5G, el Internet

6 https://www. allaccess.com/merge/archive/31294/infographic-what-happens-inan-internet-minute 
de las cosas (IOT) y la industria 4.0, auguran una próxima e inminente explosión de datos (llamada por algunos el big bang de los datos, lo cual requerirá una mayor potencia de procesamiento y recursos físicos para manejarlos).

\section{I lustración 4. El “big bang” de los datos.}

\section{La creación de datos, a punto de explotar}

Cantidad real y prevista de datos generados en todo el mundo (en zettabytes)

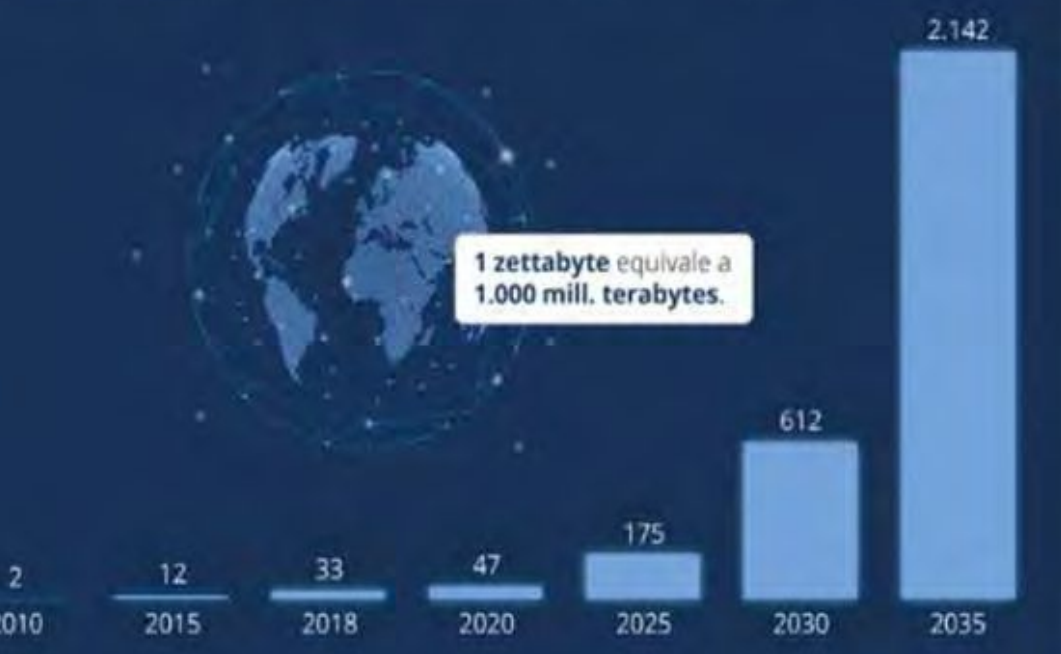

Fuente: extraído de la tercera edición del estudio Digital Economy Compass: https:// es.statista.com/page/compass

Para tener una idea de las dimensiones de los números que estamos tratando (un zettabyte son 1.000.000.000.000.000.000. 000 de bytes), podemos compararlos con dispositivos bien conocidos para intentar comprender el volumen de información generada en el año 2018: 33 zettabytes es la información que se puede almacenar en 330 millones de discos duros de gran capacidad o la que se podría almacenar en 33 millones de cerebros humanos. Y recordemos que estamos en los estadios iniciales de una inexorable explosión de datos, con previsiones que apuntan a más de 600 ZB generados para el año 2030. 


\section{I lustración 5. Equivalencia de datos generados en 2018.}

\section{La cantidad total de datos creados en 2018 equivale a}

\section{3 zettabytes Exctamano essimilara}

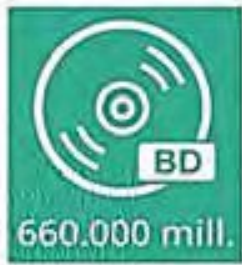

discos Blu-ray estandar

150 gigabytes cada uno)

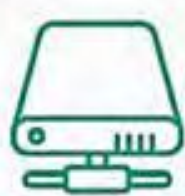

330 mill.

de los discos duros. con mayor capacidad (100 terabytes')

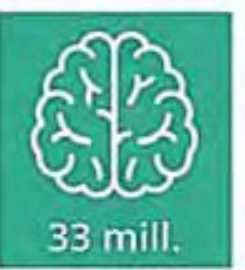

cerebros humanos (1 petabyte")

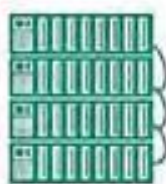

132.000

del almacenamento

de los super-

computadores

más rápidos

(250 Petabytes")

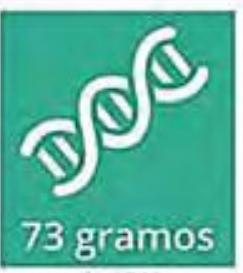

de ADN

(455 exabytes)
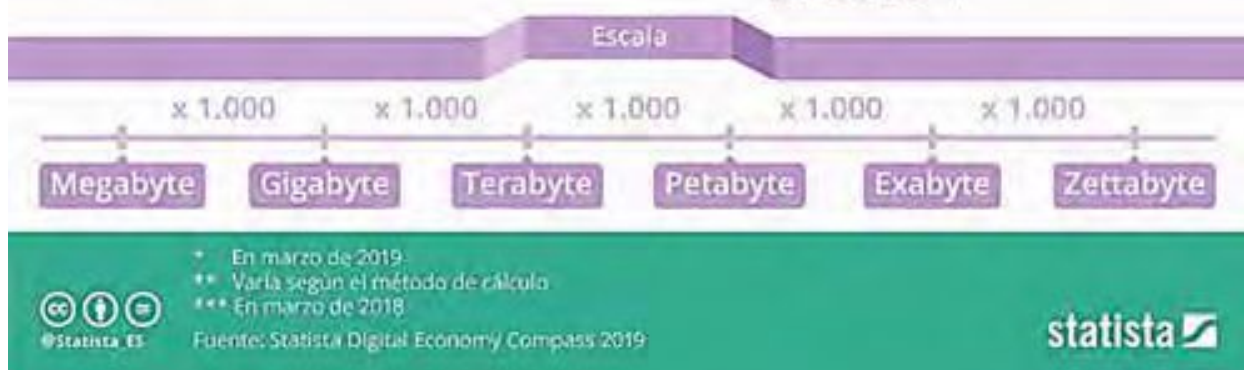

Fuente: extraído de la tercera edición del estudio Digital Economy Compass : https:// es.statista.com/page/compass

Si nos centramos en los usos de la telefonía móvil que realiza un usuario medio, vemos como, sin tener que intervenir para nada el usuario en la creación directa de esta información, el omnipresente sistema operativo Android envía datos a su propietaria Google de forma ininterrumpida. 


\section{I lustración 6. Datos generados en dispositivos móviles.}

\section{¿Qué datos se envían desde los teléfonos Android? \\ Volumen y ripo de datos transferidos de los smartphones Android a Google por dia}

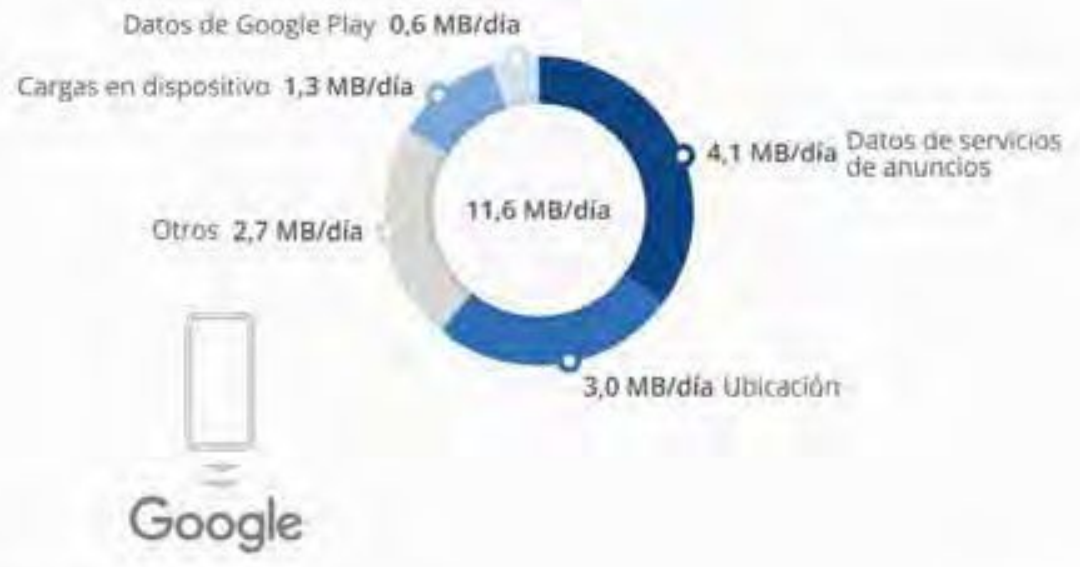

Fuente: digital context next, STATISTA: https://es.statista.com/grafico/19638/datostransferidos-de-los-smartphones-android-a-google-por-dia/

Preocupantes son también estadísticas que reflejan la cantidad de horas al día que se dedican al uso de medios digitales, pero sobre todo el incremento en el uso específico de dispositivos móviles, como se puede observar en la Ilustración 7. 


\section{Ilustración 7. Tendencias en uso de medios digitales en USA.}

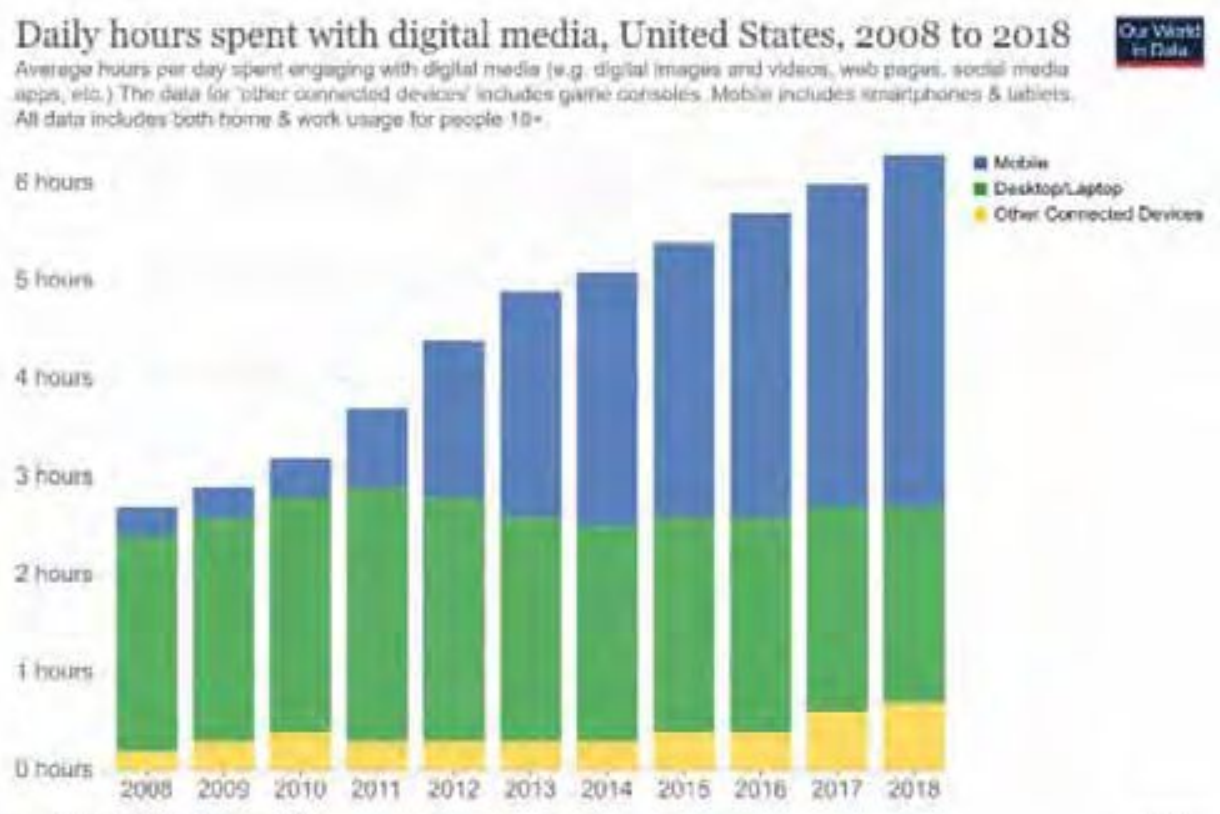

Fuente: datos extraídos de BND Internet Trends (2019): https://www.bondcap.com/ report/itr19/

Yottabytes de numeración lógica albergados en enormes bases de datos. Algunos con un sentido claro de utilidad en pro del bien común; otros, en cambio, se pueden ejercer en contra de las personas cuando se trata de obtener información que podríamos calificar de íntima. Oportunidad que se ha acrecentado con el auge del internet de las cosas, esto es la interconexión a través de Internet de dispositivos informáticos integrados en objetos cotidianos, lo que les permite enviar todo tipo de información sobre sus usuarios en aras, presumiblemente, de una mayor eficiencia y gestión para la toma de decisiones y el ahorro de tiempo. Una expresión ciertamente paradójica. Pero no nos detengamos ahora en la extrañeza de ciertas locuciones, sino en otros asuntos que acaso nos pasen desapercibidos y que sin embargo pueden tener unos efectos verdaderamente perjudiciales para los usuarios: tal es la fragrante vulneración del derecho a la intimidad (o a la privacidad, como también se la nombra), por el cual se protege de cualquier intromisión cuando pertenece a la esfera privada del individuo. Problema que desde la racionalidad instrumental le es ajeno a los desarrolladores de 
este tipo de tecnologías más centradas en el volumen de estos datos, la variedad de fuentes de las que se pueden obtener y la velocidad con la que estos se reciben y procesan para la toma de decisiones a partir de ello, lo que ha comportado un similar crecimiento en el desarrollo de la inteligencia artificial capaz de poder hacer rentables esa disposición de datos mediante la elaboración de patrones de comportamiento a disposición de empresas y gobiernos.

Ahora bien, aunque así se pretenda hacerlo creer, respecto de las empresas no podemos hablar de utilidad pública sino de oportunidad de negocio; en cambio, el uso gubernamental puede tener una doble vertiente: si se emplea como servicio o control público. Ambas requieren de datos y manejo de estos, con lo que la posesión de ellos tendrá un carácter positivo o negativo dependiendo del motivo por el cual se use; no de su logro, que acaso únicamente poner de relieve la eficiencia del sistema algorítmico.

Pues bien, ya hemos apuntado algunas ventajas de este cambio tecnológico y mencionado algunos inconvenientes, tales como la pérdida de anonimato y su instrumentalización. Pero hay más y aquí nos interesa poner de relieve lo que tiene que ver con la discriminación predictiva que puede llevarse al extremo en el ámbito sociopolítico, como veremos en epígrafes sucesivos.

\section{La discriminación predictiva}

A todas las distintas formas de discriminación, diferente y perjudicial, debemos sumarle ahora otras dos: la del paria digital o la del discriminado logarítmico. Al primero de los grupos pertenecemos todos aquellos a los que de un modo $u$ otro la intrusión de la tecnología en todo ámbito cotidiano nos imposibilita el acceso a determinados bienes antes fácilmente accesibles como eran los trámites de tipo administrativo.

Las tecnologías de la información, esas que tantas loas parece recibir en los últimos tiempos por las posibilidades de acceso a la información que favorece también crea barreras infranqueables que separa a las gentes con menos recursos o determinadas discapacidades para el acceso a información necesaria toda vez que la implantación tecnológica excluye del 
contacto humano antes facilitador de esa información. Pero hay más: no son pocos los puestos de trabajo que el uso excesivo de estas tecnologías parece haber vuelto obsoletas ( $y$ con ellas a las personas), toda vez que, excusados en la comodidad, preferimos omitir la importancia de estas labores. Otra forma más de exclusión y como el excluido es un sujeto que tiene la curiosa peculiaridad de resultar incómodo, cuando no peligroso por su falta de utilidad social, adquiere, sin pretender, matices de sospechoso disruptor de lo normalizado y que, por tanto, conviene apartar de nuestra atención, cuando no anular gracias a toda una serie de mecanismos represivos contra estos a los que no se duda en caracterizar de "enemigo" con toda la carga connotativa que ello supone, incluso en el desarrollo de un nuevo derecho de carácter excepcional.

\section{La consideración del enemigo: un derecho penal excepcional.}

El tema del enemigo, y su consideración penal dentro de las propias fronteras sociales, ha adquirido en los últimos años renovados bríos en la obra del jurista de origen alemán Günther Jakobs, quien ha dado carta de naturaleza teórica a un provocador tema que lleva por nombre "Derecho penal del enemigo", cuyos encontrados debates no se dirimen en el ámbito de la retórica ni en lo meramente terminológico, sino en las bases teóricas (explícitas ${ }^{7}$ e implícitas ${ }^{8}$ ) sobre las que se levanta el edificio argumentativo de J akobs; quien se muestra cuidadoso a la hora de diferenciar el derecho penal (ordinario) de ese otro derecho penal (excepcional) que en su aplicación diferencia a ciertos individuos (o colectivos) que pierden, en esa distinción,

7 Entre las referencias explícitas en la obra de Jakobs nos encontramos aquella consideración que sobre el enemigo realizan los modernos teóricos de contractualismo social, desde Hobbes (Elementos de filosofía, "El ciudadano", sección III, c. XV, 22) a Fichte (Fundamento del derecho natural según los principios de la doctrina de la ciencia, segunda parte o derecho natural aplicado, primera sección, De la doctrina del derecho Político: Del contrato de ciudadanía, $\S 17, \mathrm{~B}$ ), pasando por Pufendorf (De Jure Nature et Gentium, libro VIII, vol. 1, c. VI, §§ 2-5 y 8-9; c. VII, §§ 2, 5, 16), Locke (Segundo tratado sobre el gobierno civil, capítulo 2, 6), Rousseau (El contrato social, Libro II, capítulo V, "Del derecho de vida y muerte") y Kant (Sobre la paz perpetua, sección segunda).

8 Como ocurre con planteamientos expositivos del iuspublicista y filósofo alemán Carl Schmitt (en El concepto de lo político) y del sociólogo alemán Niklas Luhmann (Complejidad y modernidad), respecto de la consideración del enemigo y la noción de persona. 
toda consideración de persona, con la merma de las garantías de protección jurídica que ello supone. Y la noción clave que establece la diferencia es la de "seguridad cognitiva" 9 .

\section{La seguridad cognitiva como nuevo núcleo axiológico.}

El derecho penal (ordinario) define y sanciona aquellos delitos, o infracciones de normas, que llevan a cabo los ciudadanos de un modo incidental y que, normalmente, son la simple expresión de un abuso por parte de los mismos de las relaciones sociales en las que participan desde su status de ciudadanos, es decir, en su condición de sujetos vinculados a y por el derecho, contra el que cometerían -y así lo establece Jakobs - un desliz reparable (J akobs/Cancio: 2003, 35).

Esto es así cuando el autor, a pesar la infracción, ofrece garantías de que se conducirá, a grandes rasgos, como ciudadano, es decir, «como persona que actúa en fidelidad al ordenamiento jurídico» (Jakobs/Cancio: 2003, 36). Sin embargo, el enemigo es aquel (dentro de las fronteras sociales) que se ha apartado del derecho presumiblemente de un modo duradero (no sólo de manera incidental) y, por ello, no garantiza esa mínima seguridad cognitiva, mostrando este déficit por medio de un comportamiento contrario a las expectativas normativas vigentes en la sociedad (Jakobs/Cancio: 2003, 39 s.). De modo tal, escribe Jakobs, que «si ya no existe la expectativa seria, que tiene efectos permanentes de dirección de la conducta, de un comportamiento personal - determinado por derechos y deberes-, la persona degenera hasta convertirse en un mero postulado, y en su lugar aparece el individuo interpretado cognitivamente. Ello significa, para el caso de la conducta cognitiva, la aparición del individuo peligroso, del enemigo» (Jakobs/Cancio: 2003, 14).

9 Consideramos, además, que esta noción no se desasemeja en demasía de la exposición que hace Anthony Giddens sobre la "seguridad ontológica", que desarrolla en su obra Consecuencias de la modernidad, a partir de la diferencia que lleva a cabo entre fiabilidad y confianza. Sin bien, la deuda teórica evidente se encuentra, sobre todo, en las aportaciones hechas por Immanuel Kant (Sobre la paz perpetua, sección segunda) y Johann Gottlieb Fichte (Fundamento del derecho natural según los principios de la doctrina de la ciencia, primera parte, tercera sección, Aplicación sistemática del concepto de derecho o la doctrina del derecho, § 8, "Deducción de la división de un doctrina del derecho" y primera parte, tercera sección, Aplicación sistemática del concepto de derecho o la doctrina del derecho, capítulo l, De la doctrina del derecho: Deducción del derecho originario, § 12, "Tránsito a la investigación del derecho de coacción a través de la idea de un equilibrio del derecho"). 
Este sería el caso de individuos que, dedicados a actividades inequívocamente delictivas que operan al margen del derecho, más allá del significado de cada hecho delictivo concreto, manifiestan una dimensión fáctica de peligrosidad a la que habría que hacer frente de un modo expeditivo, sostiene Silva Sánchez (2001, 164 s.). Es decir, que, en definitiva, la aplicación del llamado derecho penal del Enemigo no atiende directamente a la comisión de hechos delictivos contra bienes jurídicos protegidos por el derecho penal, sino únicamente a la condición de peligrosidad sobre los principios políticos o socioeconómicos básicos de nuestro modelo de convivencia (Silva Sánchez: 2001, 65; Cancio Meliá, en Jakobs/Cancio: 2003, 95).

En definitiva, los enemigos son individuos que se caracterizan, primero, por su rechazo por principio a la legitimidad del ordenamiento jurídico y persiguen la destrucción de ese orden; y, segundo, a consecuencia de ello, por su especial peligrosidad para dicho orden. Con lo que sobre este se aplicaría una excepcional legislación de lucha o de guerra, cuyo único fin sería su exclusión e inocuización (Silva Sánchez: 2001, 164 s.), puesto que - afirma Jakobs - «un individuo que no admite ser obligado a entrar en un estado de ciudadanía [...] no puede participar de los beneficios del concepto de persona» (Jakobs/ Cancio: 2003, 40).

Por todo ello se explica - siguiendo al jurista alemán-que la reacción del ordenamiento jurídico frente a esta criminalidad se caracterice por la renuncia a las garantías materiales y procesales del derecho penal ordinario, pues no se trata ya, en primera línea, del castigo de una causación reprochable de daño social, sino de la eliminación preventiva de la fuente de peligro que constituye el individuo que ha sido distinguido como peligroso (Jakobs/Cancio: 2003, 40 y 42).

Estos principios y reglas propios del derecho penal del enemigo vendrían, pues, impuestos por el significado de las circunstancias fácticas que caracterizan la actividad y la posición del enemigo frente a la sociedad, y se configurarían como instrumentos adecuados para la prevención del peligro que representa dicho enemigo, estableciendo un claro enfrentamiento con los mismos. Y así lo afirma Jakobs cuando escribe que «la guerra tiene lugar con un legítimo derecho de los ciudadanos, en su derecho a la seguridad» (Jakobs/Cancio: 2003, 56). 
El riesgo potencial para el resto de la población también es, sin duda, enorme; pues si el individuo solo colma las expectativas cuando actúa de acuerdo con la norma, por medio de la conducta que de él se espera, entonces cualquier acto de disidencia puede ser susceptible de ser catalogado como desestabilizador $\mathrm{y}$, por consiguiente, al tacharlo de peligroso, volver justificado cualquier tipo de acción penal en contra; con lo que, en esa aplicación, el derecho penal no pasaría de ser un simple instrumento subordinado a la ideología de la política vigente, que en su priorización de los intereses colectivos, opone la actitud coercitiva del Estado frente a los derechos individuales de los súbditos; vulnerándose, en esa renegociación en aras de la seguridad, principios fundamentales de derecho que lesionan el principio de dignidad humana, que ahora entra en el ámbito de la negociación, ante la cual el individuo solitario no tiene posibilidad alguna de defensa.

Por eso, si el debate sobre el derecho penal del enemigo es necesario se debe, sobre todo, a que permite desenmascarar las mezquindades. Toda excepción, por el motivo que sea, anula el supuesto de la dignidad como principio y hace la vida de todos más precaria, precisamente porque su inexistencia mengua los principios y garantías del Estado de derecho (Muñoz Conde: 2005, 123-137). Eugenio Raúl Zaffaroni es prístino en este sentido: «Lo que esta respuesta desconoce es que para los teóricos -y sobre todo para los prácticos- de la excepción, esta siempre invoca una necesidad que no conoce ley ni límites [...] porque los establece el mismo que ejerce el poder. Como nadie puede prever exactamente lo que hará ninguno de nosotros en el futuro - ni siquiera nosotros mismos-, la incerteza del futuro mantiene abierto el juicio de peligrosidad hasta que quien decide quién es el enemigo deja de considerarlo tal, con lo cual el grado de peligrosidad del enemigo $-y$, por ende, de la necesidad de contención- dependerá siempre del juicio subjetivo del individualizador, que no es otro que quien ejerce el poder» (Zaffaroni: 2006). El mismo pronóstico hace Cancio Meliá, para quien «[...] no parece que el 'derecho penal' del enemigo pueda actuar de válvula de escape que relaje la presión sobre las garantías jurídico-penales del derecho penal ciudadano. De hecho, parece que el pronóstico más razonable es el contrario: que ambos no podrán convivir pacíficamente porque la presencia de una regulación en términos de derecho penal del enemigo 
acaba extendiendo su lógica más allá del campo de regulación inicial, contaminando el derecho penal en su conjunto» (Cancio Meliá: 2008, 86).

Este aspecto del derecho penal y la política criminal se ha puesto de manifiesto a raíz de los atentados del 11-S, merced a los cuales el derecho penal del enemigo se presenta como un nuevo paradigma o modelo normativo del derecho penal, cuya expresión a través de la denominada Patriot Act de los Estados Unidos de América, del 26 de octubre de 2001, y la Anti Terrorism, crime and security Bill, de Inglaterra, de 14 de diciembre de 2001, no son más que ejemplos significativos de otras tantas leyes que sancionan ex profeso y combaten contra delitos de terrorismo, criminalidad económica, criminalidad organizada, tráfico ilegal de drogas y los delitos contra la integridad sexual.

Por tanto, comprobamos que de lo que se trata es de encontrarle a este derecho un fundamento definitivo, que valide teóricamente lo que ya ocurre de facto en la política penal y penitenciaria de países como Brasil, Venezuela, México, Perú o Colombia; esto es, aquellos especialmente afectados por el narcotráfico y el terrorismo. Pero también un comportamiento cada vez más extendido mediante el proceso de criminalización que sufre la ciudadanía, o una parte de ella, que ve y vive el alejamiento y menoscabo de sus derechos, extendiendo su indignación manifestada por las calles de las ciudades o en las distintas redes sociales. Expresiones de descontento que alzan su protesta frente a la insuficiencia de los canales de cambio social, omisión de demandas, leyes inconstitucionales e injusticia manifiesta, tanto respecto de la libertad igual como de oportunidad justa, causadas por casos concretos de abuso de poder que se especifican en formas de exclusión que rompen el pacto social -en sentido lockeano- y desconocen el adagio ciceroniano "salus populi suprema lex" (De legibus, libro III, parte III, sub. VIII), del que ya había hecho uso Thomas Hobbes (Elementos del derecho natural y político II, c. IX, 1) y que, también, para Locke supone la regla más justa y fundamental (Segundo tratado sobre el gobierno civil, capítulo 13, 158).

En definitiva, no resulta descabellado pensar en la extensión del derecho penal ex profeso y ad hoc (hace ya muchos años que las reformas penales se plantean ad hoc, al calor de un problema 
concreto, en respuesta a titulares periodísticos airados, como un modo de ganar votos) contra este tipo de movimientos colectivos que se congregan en torno a una queja social.

Con ello, sin embargo, no pretendemos negar que, desde la perspectiva del riesgo, esto es, desde el punto de vista del ciudadano débil e inseguro, la construcción de un derecho penal para enemigos resulta atractiva en cierto sentido. Sin embargo, sí pretendemos poner de manifiesto que es precisamente la sociedad, víctima de creciente malestar y temor - frutos de una espiral que tiene no poco de inducida - la que cada vez se muestra más exigente respecto de las medidas penales, favoreciendo así una clara tendencia expansiva del derecho penal ordinario con respecto a los ámbitos normales de intervención de aquél. Lo que progresivamente va instaurando un cultivo propicio para la fijación del derecho penal del enemigo, justificando, en este mismo orden de ideas, la formación de una restricción de las garantías liberales en favor de una estructura política más coercitiva, incorporando nuevos tipos penales y aumentos sobre las penas a delitos señalados con vehemencia por la sociedad, y que retóricamente cae bajo la falacia ad populum (que apela a los sentimientos con el fin de que se admita una propuesta sin aportar pruebas reales).

Esta pulsión meramente afectiva, propia de -permítasenos la referencia cinematográfica - la jauría humana, conlleva el riesgo inevitable de un punitivismo agravado, establecido únicamente por un simbolismo imaginario protector, no de libertades personales ni tampoco de bienes jurídicos (puesto que el derecho penal del enemigo se opone frontalmente a la teoría del bien jurídico protegido), sino de una abstracta y formalista idea de vigencia del sistema jurídico, identificada, en la práctica, con el temor de una parte importante de la población. Con lo que el Estado de derecho genera progresivamente su propia crisis de legitimación, al implicar la pérdida de garantías individuales, consentida por la propia ciudadanía medrosa, como nos recuerda Karolina Víquez: «El derecho penal del enemigo se origina en un estado de inseguridad, en el que la población cede -convencida por una nueva política criminal - su derecho a la libertad a cambio del derecho a la seguridad» $(2007,15)$.

Para ello, el Estado y su gobierno, en connivencia con algunos medios de comunicación de masas, se encargan de 
identificar este peligro frente al que la población se solidariza en aras de su conservación, generándose una reacción masiva en contra del enemigo señalado, sobre el que se justifican las medidas represivas en nombre de la seguridad.

En efecto, el enemigo en este desarrollo del derecho penal es señalado por lo que parece (a ojos de los demás) y no por lo que hace; es decir, que el presupuesto de la pena no es sólo el factum delictivo, sino una cualidad personal determinada en cada ocasión con criterios puramente potestativos (como los de "sospechoso" o "peligroso"), en gran medida por diagnosis y prognosis políticas, con lo que es claro que el esquema puede ampliarse en múltiples direcciones: es el caso, por ejemplo, de la creciente islamofobia que se ha instalado en la parte occidental del globo, manifestada a veces en actuaciones nada garantistas. Pero incluso también de una actitud de sistemática desconfianza hacia las diversas categorías de marginados sociales. Es el caso de aquellas personas que, por la deriva de los mercados económicos, de las oportunidades reales y efectivas de empleo (y las posibilidades de integración que ello supone), se encuentran discriminadas por una sociedad de consumidores satisfechos que advierten en aquellos una indeseable incomodidad por el solo hecho de no manifestar - de nuevo solo por razones meramente circunstanciales - la escala de valores socialmente reconocida, llegando el propio Estado incluso a legislar en su contra (caso de la criminalización de la pobreza).

Es entonces cuando, más allá de la constatación de un retroceso de las garantías del Estado de derecho, también parece evidenciarse una franca retirada del Estado benefactor ${ }^{10}$.

\section{A modo de conclusión: la evaluación algorítmica de la amenaza social}

Nada de cuanto hemos dicho en páginas anteriores debería extrañar al lector informado, ya que no son pocos los modos de exclusión social de los que a buen seguro tiene conocimiento.

10 El concepto de "Estado benefactor" encierra la idea de que entre las obligaciones del Estado está la de garantizar a toda la población una situación de "bienestar"; y esto implica algo más que la simple supervivencia: es una supervivencia con dignidad, entendida tal como la concibe cada sociedad en su propia época. 
La reciente tecnología, como vimos al principio de nuestro escrito, no cambia esos procederes, los acrecienta. Riesgo que para todos se acentúa con modelos informáticos como Crime Predicting Software, programas que intentan predecir las tendencias criminales de las personas o pretenden elaborar mapas de potenciales áreas de tensión en las ciudades. Ya no solo se trata del menesteroso, el marginado, la minoría racial, sino que el riesgo de este algoritmo se extiende a toda la población.

La excusa oportuna siempre será la misma: generar una confianza de seguridad; la motivación, ante los temores que se puedan destacar utilizando también este tipo de algoritmos para la información, no será otra que la oclocracia como pretexto político.

Desde este comportamiento queda ya respondida toda duda respecto a si la idea de seguridad, a partir de nociones como las de riego y peligro, debiera fungir como núcleo axiológico del derecho. De hecho, lo hace ante la demanda de una ciudadanía medrosa, siempre tendente a la exclusión y la culpabilización.

Ante esta constatación cabe preguntar ¿qué parte de responsabilidad tenemos cada uno de nosotros en esta retirada del Estado garantista? Toda, ciertamente, como no hemos disimulado en señalar; y eso desde las primeras cookies informáticas que aceptamos sin queja significativa si queremos un mínimo acceso a alguna información de nuestro interés ${ }^{11}$.

11 Por defecto las ventanas emergentes que aparecen al consultar una página web contienen un botón bien visible de "Aceptar" el cual la mayoría de los usuarios activan de forma impulsiva para poder acceder a la información buscada sin tener ni idea de a qué están dando permiso, mientras que unos pocos sitios web permiten la configuración del navegador para el comportamiento de este en relación a las cookies de esos sitios en concreto. Las cookies son archivos que se almacenan en nuestro navegador y obtienen datos sobre nuestras búsquedas y aunque la mayoría de ellas se utilizan para personalizar la publicidad que nos presentan en las páginas web, también pueden tener otros propósitos: técnicos (control, identificación y almacenamiento de los contenidos buscados), personalización (almacenan idioma, tipos de navegador, región...), de análisis (acerca del comportamiento del usuario) y comportamental (crean un perfil específico del usuario); seguramente la más problemática desde el punto de vista de la privacidad. De hecho, según una sentencia del Tribunal de Justicia de la Unión Europea (TJUE) no es válido que un sitio web muestre una casilla marcada por defecto en la que el usuario debe retirar la marca para evitar la colocación de cookies en su ordenador, el usuario debe dar su consentimiento expreso. Además, el TJUE añade que el proveedor de los servicios debe informar claramente sobre qué cookies van a instalarse, con qué objetivo, a qué terceros va a darse acceso y durante cuánto tiempo estarán activas las cookies en el equipo, para que el usuario pueda decidir si consiente su instalación (http://www. consultoria-conversia.es/ley-de-cookies/aceptacion-cookies-requiere-consentimientoactivo/). A pesar de todo ello según un estudio de la empresa PrivacyCloud, sólo el $14 \%$ de las páginas web más usadas en España se han adecuado al Reglamento General de 
Esos progresivos consentimientos, son los que han abonado el terreno a programas como Eurocop, Precobs, XLAW - Hart, retóricamente amparados bajo la bienhechora idea de la seguridad ciudadana. Dicha expresión está conectada con un enfoque preventivo, poniendo el énfasis en la protección de los derechos individuales y fundamentales de todos los ciudadanos. Se trata, por tanto, de un concepto que contrasta con el de "seguridad nacional" que dominaba el discurso público en décadas pasadas y que se enfocaba más en la protección y la defensa del propio Estado. Pero, desde un punto de vista empírico, las políticas gubernamentales de seguridad ciudadana han llegado a confundirse con una noción como la de Defensa de Estado, a través de unas fuertes políticas represivas que acrecientan más la situación de desamparo por parte de la ciudadanía en su conjunto; porque, admitámoslo, todos somos potenciales disruptores del orden social cuando sufrimos los envites de determinadas políticas laborales que deprecian derechos laborales, se promueven políticas de recorte presupuestario que amenazan las bases del Estado de bienestar o se favorece todo tipo de tropelías financieras con la connivencia de los grupos parlamentarios y el Ejecutivo, no menos consintiente con las prácticas empresariales que deterioran el entorno natural y menoscaban las posibilidades vitales de cuantos puedan ser afectados de un modo más o menos directo, y sobre lo que muchos de nosotros creemos estar al margen de dichas responsabilidades.

Sin embargo, conviene recordarle al lector, que cada búsqueda que realizamos en internet libera al medio ambiente $0,2 \mathrm{~g}$ de $\mathrm{CO}_{2}$. Basta, tan solo, multiplicar por la cantidad de búsquedas que cada usuario realizamos a diario por la red de redes para darnos siquiera mínimamente cuenta de lo que respecto de las emisiones de $\mathrm{CO}_{2}$ suponen esos usos.

De hecho, tratando de ser un poco más específicos, según un estudio de la investigadora J oana Moll en el cual se monitorea las emisiones del buscador de internet Google, dicho estudio concluye que cada segundo solo este buscador emite más de

Protección de Datos (RGPD), de plena aplicación desde mayo de 2018, el 99\% incumplen la obligación de permitir al usuario rechazar las cookies con la misma facilidad que las pueden aceptar, y el $9 \%$ de las webs obligan a los usuarios a aceptarlas si quieren seguir visitando los contenidos de la página. 
$500 \mathrm{~kg}$ de $\mathrm{CO}_{2}$ a la atmósfera. Pero esta es solo una ínfima parte que quizá no suponga tanta sorpresa como sí estimamos que provoque la atención puesta en el total del sector de las tecnologías de la información (Ilustración 8):

\section{I lustración 8 Consumo eléctrico del sector de IT}

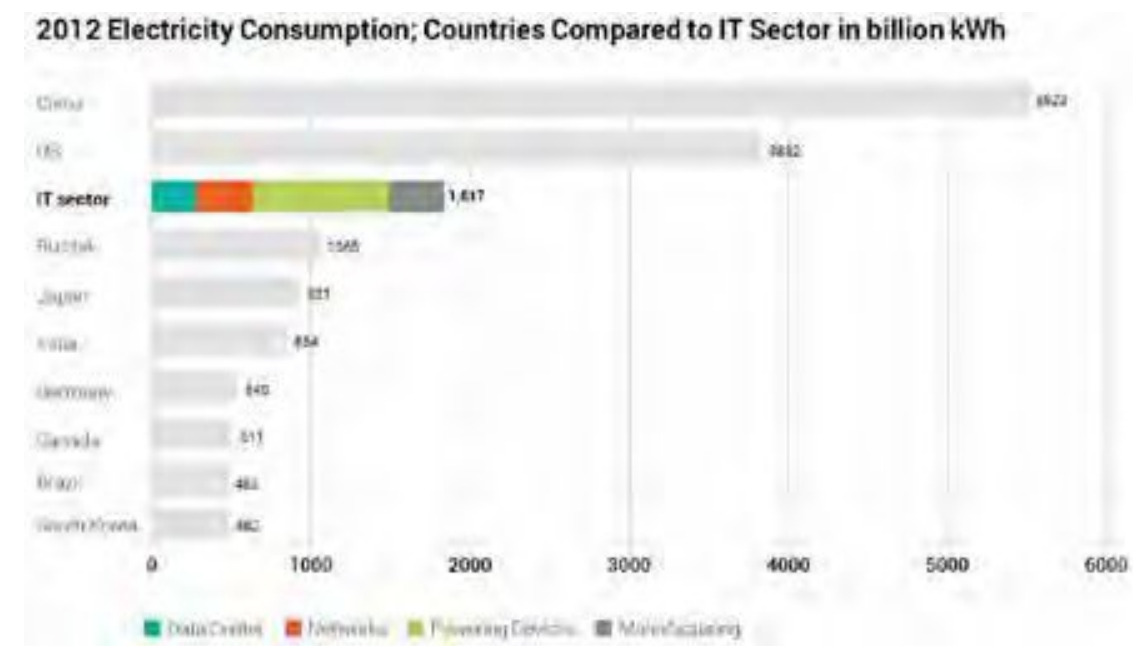

Fuente: Emerging Trends in Electricity Consumption for Consumer ICT, Peter Corcoran and Andres Andrae (2013) and ClA World Factbook. China/Russia/Canada. Figures are from 2014

Como se aprecia, el sector de las tecnologías de la información consumió en el año 2012 el doble de electricidad que países como Japón y casi 4 veces más que Alemania, situándose, tras China y los Estados Unidos, como el tercer gran consumidor de energía eléctrica. Sin duda, pues, este también es uno de los grandes retos cuando de legislación climática se habla tanto a nivel nacional como internacional. Pero no solo, ya que, asociado a esa acelerada carrera tecnológica, otro de los grandes retos implica a los propósitos de frenar la escalada de generación de residuos, y su costoso y complejo tratamiento posterior. 
Todos estos desechos -o externalidades, como eufemísticamente suele designárselos - incluyen calculadoras, cámaras, ordenadores portátiles, dispositivos móviles y demás dispositivos electrónicos que, siguiendo el actual sistema de valores establecido por los medios de comunicación, se quedan obsoletos de un año para el siguiente sin ninguna razón objetiva ni técnica, excepto la de engrasar la gran maquinaria capitalista ${ }^{12}$.

El hecho de que este tipo de residuos presente cada vez más complejidad en sus ensamblajes no ayuda tampoco en su posterior tratamiento. Ni siquiera el que contengan cada vez más materiales escasos en la corteza terrestre (tierras raras) contribuye al replanteamiento de intentar recuperar esos materiales tan valiosos. Así pues, por mucho que desde los medios de comunicación se nos abrume con datos sobre reciclaje o acerca del tratamiento de residuos, la realidad es que toda la basura electrónica generada en el mundo acaba en zonas de China, India o África (ver ilustración 9), donde su presumible reciclaje consiste poco más que en incinerar los residuos sin ningún tipo de medidas de seguridad ni control de emisiones, generando terribles consecuencias tanto para el medio ambiente como para las personas que trabajan en estos vertederos electrónicos.

12 Se estima que en el año 2025 se generarán cerca de 54 millones de toneladas de desechos electrónicos, de los cuales 10 millones se producirán en Europa (https:// www.nationalgeographic.es/medio-ambiente/2018/06/europa-generara-mas-de-10millones-de-toneladas-de-basura-electronica-en). 


\section{l lustración 9. Flujos mundiales de basura electrónica.}

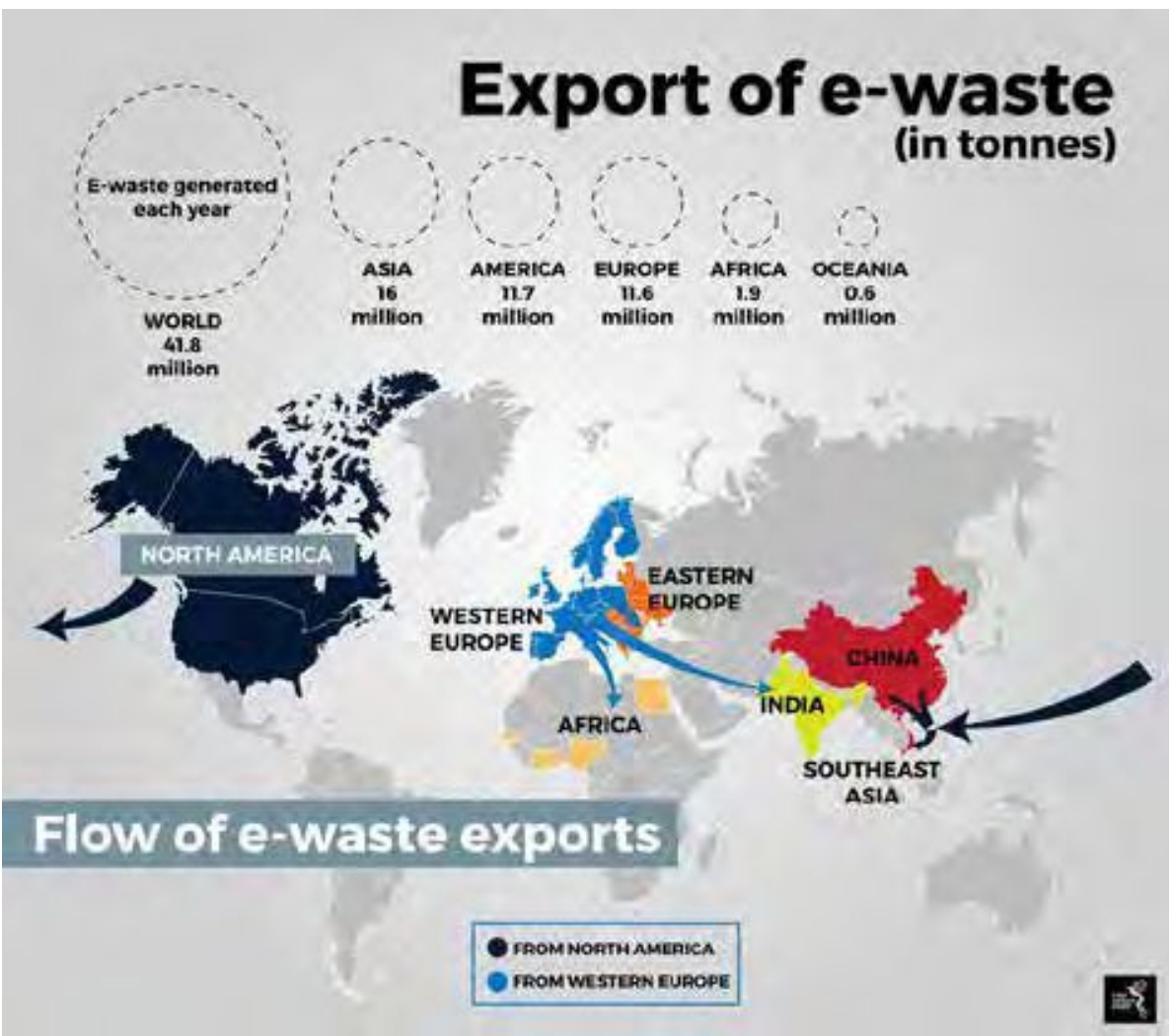

Fuente: https://www.ban.org/news/2018/11/5/e-waste-chokes-southeast-asia

No obstante, dudar de la idoneidad de este orden favorecido y manifestarse en contra nos señala como insumisos $y$, por ende, dependiendo del ruido generado, enemigos que conviene inocuizar; para lo cual las herramientas algorítmicas de control prestan una oportuna ayuda, no solo en la perfilación discriminatoria sino también -como con el uso del software Cortica - previendo cuándo una manifestación ciudadana puede volverse violenta.

He aquí el mundo orwelliano al que nos han conducido el big data y la inteligencia artificial que lo ordena según un determinado sesgo; concluimos, recordando al lector que hasta aquí haya tenido la paciencia de llegar, qué ocurre con aquellos que como Edward Snowden ponen sobre aviso que, tras la comodidad que nos proporcionan las nuevas tecnologías (aunque nos hagan 
cada vez más inútiles para otros menesteres antes sencillos) y el divertimento que nos proporcionan los micro-estímulos de nuestras redes sociales (que nos vuelve desatentos a la realidad circundante), somos mercancía en manos de Amazon, Microsoft y Yahoo!, Google, Apple, Facebook, Twitter, Instagram..., ya que todo tecleo por estos programas es información apropiable gracias a la interconectividad que va en aumento con avances como el 5G, favoreciendo aún más ese llamado "capitalismo de vigilancia", en el cual ya no somos clientes sino mercancía en manos de estas compañías (Zuboff: 2019, 47-48).

No obstante, cabe preguntar: ¿es posible la desconexión voluntaria? Preguntémonoslo de otro modo: ¿Estamos dispuestos a auto-marginarnos? Si la respuesta es prudentemente negativa, ¿qué lugar le queda al debate ético-político sobre la privacidad, intimidad y protección de datos? Ya tienen la respuesta, máxime en tiempos del post-covid cuando se está promoviendo el seguimiento de la ciudadanía a través de las redes móviles; lo que, por supuesto siempre en aras de la seguridad, comporta la obligatoriedad de estar constantemente actualizados y conectados (léase, igualmente, vigilados).

De fondo persiste la misma idea axiológica de la seguridad, con lo que los riesgos ya apuntados en líneas anteriores se hacen cada vez más extensibles. De hecho, la urgencia de las medidas tomadas al amparo de la pandemia, han traído consigo la implantación de ciertas herramientas tecnológicas de una manera un tanto atropellada, obviando así todo tipo de legislación existente sobre el tratamiento de los datos personales, ya que las diferentes aplicaciones que se instalan para ello en los dispositivos móviles apuntan a un mismo objetivo: crear perfiles ciudadanos de su ubicación, ocupación, trayectos, contactos y posibles síntomas ${ }^{13}$.

13 El instituto Robert Koch ha desarrollado una app que recaba datos de las pulseras fitness para identificar alteraciones en los patrones de sueño de los usuarios y trazar mapas de propagación de infección; Vodafone por su parte ha desplegado cámaras térmicas en el Reino Unido para medir la temperatura de sus ciudadanos en todo momento; Apple y Google ha empezado a distribuir en todo el mundo una app que permite rastrear personas que han estado en contacto con un contagiado en las últimas semanas. Aunque, a diferencia de otros países como China, Corea del Sur o Singapur, donde las aplicaciones usan directamente datos sensibles de los usuarios, las soluciones que se están desplegando en Europa usan datos anonimizados, por lo que el grado de privacidad es bien distinto. Un estudio del Imperial College revelo que es posible volver a identificar al 99,98\% de las personas con solo 15 características demográficas (Rocher et al., 2019). Todo este debate puede encenderse aún más si se pone en la balanza el hecho altamente probable de que estos datos puedan caer en manos de cibercriminales por las nulas o casi inexistentes medidas de seguridad de la inmensa mayoría de los 
En conclusión, si hablamos de retos de las tecnologías de la información y comunicación, los "big data" y la inteligencia artificial para el derecho y las administraciones públicas, no cabe duda de que este es el de la privacidad; la oportunidad que se inicia es anteponer todo tipo de cautelas para evitar la tendencia totalitaria que conlleva que la obligatoriedad tecnológica y el uso masivo de datos que se deriva de esta hiper-conectividad.

\subsection{Pero los problemas no acaban aquí.}

Volviendo sobre el tema climático y medioambiental, con los que iniciábamos nuestro escrito y sobre los cuales ya hicimos algunas observaciones referidas al aumento y obsolescencia de estos dispositivos a los que nos fuerza la interconectividad, parecería absurdo insistir en la necesidad de un cambio significativo... el mundo, físico y digital, no se mueve realmente por esas consideraciones. ¿Pero podría? Digámoslo a las claras: no sin la desconexión.

\subsection{Excurso al hilo de la idea de la desconexión}

El último de los apuntes realizados nos abría la posibilidad de pensar otros escenarios para la vida política. Una reflexión que también merece su lugar en una publicación como la presente, si quiera para tratar de contrarrestar todo exaltado optimismo tecnológico que, a la postre, puede llegar a resultar fatal; pues sepa el lector que tanto si tomamos este tipo de decisiones de forma voluntaria (esto es, la progresiva desconexión en el corto plazo) como si seguimos navegando a favor de la corriente imperante (el avance en la interconectividad), la realidad es que esta desenfrenada carrera tecnológica sustentada en el consumo de materiales ya de por si escasos y en un cada vez mayor flujo de energía, no podrá mantenerse durante mucho más tiempo. Dicho de manera llana: el dataísmo tiene sus días contados, menores de seguir al ritmo que pretenden que se produzca para mantener el llamado "big bang" de los datos, ya que cualquier tipo de futuro hiper-tecnificado que nos ofrece desde cualquiera de los frentes tecnológicos actuales, choca 
inexorablemente con una verdad incontestable: el planeta que habitamos tiene unas dimensiones finitas (Capellán-Pérez et al., 2014 y 2020); por tanto, cualquier intento de extraer más recursos, tanto energéticos como materiales, de los que dispone el sistema tierra (incluida su capacidad para albergar residuos), conducirán irremediablemente a un colapso de todo el sistema que actualmente nos sustenta.

Por todo ello la desconexión tanto digital como energética será un hecho. La única diferencia radica en que esta se produzca como consecuencia de una decisión voluntaria y a un ritmo adecuado, o una decisión impuesta por la realidad, brusca y altamente traumática.

Evitar esto último es el gran reto del derecho y de las Administraciones Públicas del Estado para los tiempos venideros. Por el contrario, despistar esta cuestión y sumergirnos en tecnocientíficas fantasías, nos arrastrará, más pronto que tarde, a la barbarie en un mundo cada vez más escaso.

Pensémoslo antes de enviar cualquier tontería a la red de redes y dar pábulo a cualquier nadería, o reconozcamos que no estamos listos, no lo pretendemos, para enfrentar ninguna de las negatividades que hasta aquí se han plasmado. ¿Por qué iba a ser distinto el derecho que establece que desde los parlamentos se elabora, los consecuentes procederes del gobierno de turno y, por ende, el funcionamiento de las administraciones del Estado y sus funcionarios? Exacto, todo ello es reflejo de su ciudadanía, y que de lo peor que está por venir no podremos librarnos con la misma facilidad del toque rápido con el que abrimos, cerramos o cambiamos de pantalla. La realidad no es así. 


\section{Bibliografía}

Aller, G. (2006): "El derecho penal del enemigo y la sociedad del conflicto", en Co-responsabilidad social, sociedad del riesgo y derecho penal del enemigo, Montevideo, Carlos Álvarez-Editor, pp. 163-270.

Aponte, Alejandro C. (2005): ¿Derecho penal del enemigo o derecho penal del ciudadano? Günther Jakobs y las tensiones de un derecho penal de la enemistad, Temis, Bogotá.

Cancio Meliá, M. (2002): “Derecho penal del enemigo y delitos de terrorismo. Algunas consideraciones sobre la regulación de las infracciones en materia de terrorismo en el código penal español después de la LO/2000", en Revista Jueces para la Democracia, $\mathrm{n} .^{\circ} 44$.

- (2008): “'Derecho penal' del enemigo: contexto político-criminal y concepto teórico. Algunas tesis sobre la construcción de Günther Jakobs", en Teoría funcional de la pena y de la culpabilidad: Seminario con Günther Jakobs en la UAM, pp. 63-87.

Cancio Meliá, M. y Gómez-Jara Díez, C. (Eds.) (2006): Derecho penal del enemigo. El discurso penal de la exclusión, Vols. 1 y 2, D de F.

Capellán-Pérez, Iñigo; Blas, Ignacio de; Nieto, Jaime; Castro, Carlos de; Miguel González, Luis Javier; Carpintero, Óscar; Mediavilla, Margarita; Lobejón, Luis Fernando; Ferreras-Alonso, Noelia; Rodrigo, Paula; Frechoso, Fernando \& Álvarez-Antelo, David (2020): MEDEAS: a new modeling framework integrating global biophysical and socioeconomic constraints. Energy Environ. Sci., 2020, 13, 986-1017. DOI: 10.1039/C9EE02627D.

Capellán-Pérez, I., Mediavilla, M., de Castro, C., Carpintero, Ó., \& Miguel, L. J. (2014). Fossil fuel depletion and socio-economic scenarios: An integrated approach. Energy, 77, 641-666. https://doi.org/10.1016/j.energy.2014.09.063

Demetrio Crespo, E. (2005): “El 'derecho penal del enemigo'. Darfnicht sein! Sobre la ilegitimidad del llamado 'derecho penal del enemigo' y la idea de seguridad", en Biblioteca Jurídico Virtual del Instituto de Investigaciones Jurídicas de la UNAM, pp. 83-114.

- (2006): "Libertad, seguridad, sociedad del riesgo y derecho penal del enemigo", en Bermuz Benítez, María J osé y Pérez, Ana Isabel (Coords.), La tensión entre libertad y seguridad, Universidad de la Rioja.

Eser, A. (2004): "Consideraciones finales", en La Ciencia del derecho penal ante el nuevo milenio, AA. VV., trad. Carmen Gómez Rivero, Valencia, Tirant lo Blanch.

- (2001): “Una justicia penal 'a la medida del ser humano' en la época de la europeización y la globalización", en Modernas tendencias en la Ciencia del derecho penal y en la Criminología, Aa. Vv., trad. Teresa Manso Porto, Madrid, Universidad Nacional de Educación a Distancia.

Feijóo Sánchez, B. (2006): El derecho penal del enemigo y el Estado democrático de derecho, Estudios penales y política criminal, México, 2006.

Fernández, Gonzalo D. (1988): Derecho penal y derechos humanos, Montevideo, Instituto de Estudios Legales y Sociales del Uruguay.

Ferrajoli, L. (2009): Derecho y razón. Teoría del garantismo penal, Madrid, Editorial Trotta.

- (1999): Derechos y garantías. La ley del más débil. Madrid. Trotta.

- (2006): "El derecho penal del enemigo y la disolución del derecho penal", en Questione Giustizia 2/2006, en Jueces para la Democracia.

Fichte, J. G. (1994): Fundamento del derecho natural según los principios de la doctrina de la ciencia. Trad. de I. L. Villacañas, M. Ramos y F. Oncina. Est. int. de I. L. Villacañas. Madrid, Centro de Estudios Constitucionales.

Foucault, M. (2009): Vigilar y castigar. Nacimiento de la prisión, Madrid, Siglo XXI. Gracia Martín, L. (2006): El horizonte del finalismo y el "derecho penal del enemigo", Editorial Tirant Lo Blanch, Valencia. 
Gracia Martín, L. (2005): “Consideraciones críticas sobre el actualmente denominado 'derecho penal del enemigo'", en Revista electrónica de ciencia penal y criminología, $N^{\circ} 7$, pp. 1-43.

- (2005): El horizonte del finalismo y el derecho penal del enemigo, Valencia, Editorial Tirant Lo Blanch.

Grocio, H. (1987): Del derecho de la guerra y de la paz. Madrid. Centro de Estudios Constitucionales.

Hobbes, Th. (2002): Diálogos entre un filósofo y un jurista y escritos autobiográficos. Madrid. Tecnos.

- (1987): Del ciudadano y Leviatán. Madrid. Tecnos.

- (1979): Elementos de derecho natural y político. Madrid. Centro de Estudios Constitucionales.

- (1998): Leviatán. México. Fondo de Cultura Económica.

- (1999): Tratado sobre el ciudadano. Madrid. Trotta.

Hubbert, (1956): M.K. Hubbert, Nuclear Energy and the Fossil Fuels. Shell Development Company (1956). Exploration and Production Research Division. Publication No. 95

Hume, D. (2006): Ensayos políticos. Madrid. Tecnos.

Jakobs, G. (1997): "Criminalización en el estadio previo a la lesión de un bien jurídico", en Estudios de derecho penal, Madrid, Civitas.

- (2002): "Derecho penal del enemigo y delitos de terrorismo. Algunas consideraciones sobre la regulación de las infracciones en materia de terrorismo en el código penal español después de la LO/2000", en Revista Jueces para la Democracia, $\mathrm{n}^{\circ} 44$.

- (2004): "La autocomprensión de la Ciencia del derecho penal ante los desafíos del presente", en La Ciencia del derecho penal ante el nuevo milenio, Aa. Vv., trad. Teresa Manso Porto, Valencia, Tirant lo Blanch.

- (2001): ¿Qué protege el derecho penal: bienes jurídicos o la vigencia de la norma?, Mendoza, Ediciones J urídicas Cuyo.

- (1998): Sociedad, norma, persona en una teoría de un derecho penal funcional, Bogotá, Universidad Externado de Colombia.

Jakobs, G. y Cancio Meliá, M. (2003): derecho penal de enemigo, Madrid, Editorial Thompson Civitas.

Kant, I. (1991): Antropología en sentido pragmático, Madrid, Alianza.

- (1997): Crítica del juicio, Madrid, Austral.

- (2002): Crítica de la razón práctica, Salamanca, Ediciones Sígueme.

- (1996): Crítica de la razón pura, Madrid, Alfaguara.

- (1996): Fundamentación de la metafísica de las costumbres, Madrid, Espasa Calpe.

- (2006): I deas para una historia universal en clave cosmopolita y otros escritos sobre Filosofía de la Historia, Madrid, Tecnos.

- (1978): Introducción a la teoría del derecho. Madrid, Centro de Estudios Constitucionales.

- (1988): Lecciones de Ética, Barcelona, Crítica.

- (1999): Metafísica de las costumbres, Madrid, Tecnos.

- (2003): Pedagogía, Madrid, Akal.

- (1998): Sobre la paz perpetua, Madrid, Tecnos.

- (2000): Teoría y práctica, Madrid, Tecnos.

Khulen, L. (2003): “El derecho penal del futuro", en Crítica y justificación del derecho penal en el cambio de siglo, pp. 225-229.

Locke, J. (1999): Ensayo y Tratado sobre la tolerancia, Madrid, Alianza.

- (2010): Segundo tratado sobre el Gobierno Civil, Madrid, Editorial Tecnos.

Montesquieu (1998): Del Espíritu de las Leyes, Madrid, Tecnos.

Muñoz Conde, F. (2005): “De nuevo sobre el 'derecho penal del enemigo'”, en Revista Penal, № 16, pp. 123-137.

- (2005): “El nuevo derecho penal autoritario: consideraciones sobre el llamado 'derecho penal del enemigo'", en Mutaciones de Leviatán. Legitimación de los nuevos modelos penales, Aa. Vv., Madrid, Akal. 
- (2003): Derecho penal del enemigo, Conferencias magistrales, $\mathrm{n}$. 6, México, INACIPE.

- (2004): La ciencia del derecho penal ante el nuevo milenio, Tirant Lo Blanch, Valencia.

Muñoz de Baena Simón, J. L. (2007): “Sujeto y sistema. Las transformaciones en la doctrina del derecho subjetivo durante el XIX", en Anales de la Cátedra Francisco Suárez, 41, pp. 217-236.

- (2011): "De Vivir a Cube: algunas notas sobre la tendencia totalitaria de la juridicidad moderna", en Aguilera, R. E. y Gómez, J. A. (coords.): Derecho y política a través de las artes narrativas (Desarrollos didácticos y curriculares), Monterrey, CECyTE, pp. 59-87.

- (2012): El ocaso de la política. Carl Friedrich von Gerber y la ciencia jurídica alemana. Granada, Comares.

Núñez Leiva, J. I. (2009): “Un análisis abstracto del derecho penal del enemigo a partir del constitucionalismo garantista y dignatario", en. Política criminal, Vol. 4, $\mathrm{N}^{\circ}$ 8, Art. 3, pp. 383-407.

- (2003): La dignidad de la persona desde la filosofía del derecho, Madrid, Editorial Dykinson.

Pérez del Valle, C. (2008): "La fundamentación iusfilosófica del derecho penal del enemigo. Precisiones sobre la interpretación de Kant", en Revista Electrónica de Ciencia Penal y Criminología, RECPC 10-03.

Piorno Garcel, M. (2010): "derecho penal del enemigo, ¿solución o caos?", en Aletheia. Cuadernos críticos de derecho, n. 2, pp. 72 y ss.

Portillas Contreras, G. (2004): “Fundamentos Teóricos del derecho penal y Procesal Penal del enemigo", en Revista Jueces para la Democracia, $n^{\circ} 49$, pp. 43 y ss.

Pufendorf, S. (1995): De Jure Nature et Gentium. Nueva York, William S. Hein \& Co.

- (2002): De los deberes del hombre y del ciudadano según la Ley Natural, Madrid, Centro de Estudios Políticos y Constitucionales.

Prittwitz, C. (2004): “Derecho penal del enemigo", en La Política criminal en Europa, Aa. Vv., trad. Juan Carlos Hortal I barra, Barcelona, Atelier.

Ramos Vázquez, J. A. (2007): "Algunos apuntes sobre el carácter retórico de la actual crítica al derecho penal del enemigo", en AFDUDC, 11, pp. 761-774.

Riquert, Fabián L. y Palacios, Leonardo P. (2003): “El derecho penal del enemigo o las excepciones permanentes", en La Ley, Revista Universitaria, Año V, № 3, junio, p. 1-8.

Rocher, L., Hendrickx, J. M., \& de Montjoye, Y.-A. (2019). Estimating the success of re-identifications in incomplete datasets using generative models. Nature Communications, 10(1), 3069. https://doi.org/10.1038/s41467-019-10933-3

Rousseau, J -J . (2001): Discurso sobre el origen y los fundamentos de la desigualdad entre los hombres y otros escritos, Madrid, Tecnos.

- (2003): Emilio, Madrid, Alianza Editorial.

- (1994): Contrato social, Madrid, Edaf.

Schünemann, B. (2004): “Derecho penal del enemigo: ¿análisis crítico o programa del derecho penal?", en La política criminal en Europa, pp. 112-116.

Silva Sánchez, J-M. (2002): Aproximación al derecho penal contemporáneo, Barcelona, Bosch.

- (2000): "El Retorno de la inocuización. El caso de las reacciones jurídico penales frente a los delincuentes sexuales violentos", en Estudios de derecho penal, Biblioteca de Autores Extranjeros 5, Grigley, Lima.

- (2001): La expansión del derecho penal, Madrid, Civitas.

- (2007): "Los indeseados como enemigos. La exclusión de seres humanos del status personae", en Revista Electrónica de Ciencia Penal y Criminología, RECPC09-01.

Schmitt, C. (1999): El concepto de lo político, Alianza Editorial, Madrid.

- (2006): Legalidad y legitimidad, Granada, Editorial Comares.

Spinoza, B. (1985): Tratado teológico-político. Tratado político. Madrid, Tecnos.

Víquez, K. (2007): "Derecho penal del enemigo ¿Una quimera dogmática o un modelo orientado al futuro?", en Política criminal, N³, A2, pp. 1-18. 
Zaffaroni, E. R. (2008): "Buscando al enemigo: de Satán al derecho penal cool", en Revista Científica Equipo Federal de Trabajo, Núm. 43, Diciembre; trad. italiana: "Alla ricerca del nemico: da Satana al diritto penale cool", en Studi in onore di Giorgio Marinucci, Giuffrè, Milano, ed. de E. Dolcihi y C. E. Paliero, 2006, vol. 1, pp. 757-780.

- (2006): El enemigo en el derecho penal, Buenos Aires, Ediar.

- (2005): "La legitimación del control social de los 'extraños'”, en Dogmática y Criminología. Dos visiones complementarias del fenómeno delictivo. Homenaje de los grandes tratadistas a Alfonso Reyes Echandía, Aa. Vv., Bogotá, Legis.

- (2004): “Las 'clases peligrosas': el fracaso de un discurso policial prepositivista”, en El penalista liberal. Controversias nacionales e internacionales en derecho penal, procesal penal y criminología. Manuel de Rivacoba y Rivacoba homenaje, Aa. Vv., Buenos Aires, Hammurabi.

- (2005): “¿Es posible un derecho penal del enemigo no autoritario?”, en Homenaje al Profesor Dr. Gonzalo Rodríguez Mourullo, Aa. Vv., Madrid, Thomson-Civitas, pp. 1077 ss.

Zuboff, Shoshana (2019). The age of surveillance capitalism: the fight for a human future at the new frontier of power. New York: PublicAffairs. 
